\title{
Taking into account protective works in land-use planning for mountain torrential floods: state of the art of present French practices
}

\author{
Félix Philippe ${ }^{1, \text { a }}$, Simon Carladous ${ }^{1,2,3}$, Jean-Marc Tacnet ${ }^{1}$ and Philippe Bouvet ${ }^{4}$ \\ ${ }^{1}$ University Grenoble Alps, Irstea,UR-ETGR, 2 rue de la Papeterie-BP 76, F-38402 St-Martin-d'Hères, France \\ ${ }^{2}$ AgroParisTech, Paris Institute of Technology for Life, Food and Environmental Sciences, Paris, France \\ ${ }^{3}$ Ecole Nationale Supérieure des Mines, Saint-Etienne, France \\ ${ }^{4}$ Office National des Forêts - Service Restauration des Terrains en Montagne des Hautes-Alpes, Gap, France
}

\begin{abstract}
In 1995, a law stated a common regulatory natural risk zoning for French municipalities through a land-use planning procedure called Risk Prevention Plan (PPR). In mountain valleys and especially within torrential watersheds, considering protective structures in those plans is an actual concern. Those protections do have an effect on phenomena and modify hazard and risk levels. This paper gives an overview on how torrential protective works are taken into account in present risk prevention plans. To carry out this study, 53 recent risk prevention plans over 11 French mountain departments were selected and analyzed through a common analysis grid. Torrential protection works are taken into account in more than one third of analyzed plans. Protections mostly considered are dikes, bank protections, check-dams and sediment traps. Modalities of integration of these structures vary from one plan to another, influencing both hazard and regulatory zoning. Results also show a wide range of practices between departments and even inside them. Conclusions brought out enhance knowledge about actual practices which were not sufficiently known so far. Findings and new additional recommendations will be included in a future PPR methodological guide exclusively suited for torrential context, which is currently still missing.
\end{abstract}

\section{Introduction}

Lawful hazard and risk mapping are one of the most used non-structural measures to reduce exposition and vulnerability of people and infrastructures in many western European countries [1]. France has a particularly long historical experience in the matter starting from the Submersible Surfaces Plan (PSS) created in 1935, to the Risk Prevention Plans (PPR) enforceable against third parties since a law promulgated in 1995 . These plans aim at defining areas which meet specific land-use rules (and especially constructability rules) over French municipalities according to a natural hazard zoning. The latter can be delimited following intensity, likelihood of occurrence and spatial extent of potential events [2]. In order to support PPR establishment, several methodological guides were published by the Ministry of Ecology, Sustainable Development and Energy (MEDDE). General guidelines were drawn in 1997 [3]. They were followed by specific guides for ground movements (1999) [4], lowland's floods (1999) [5] and lately avalanches (2015) [6]. Specific guidelines are being implemented for torrential floods, leading to serious damage in mountain areas through brief and intense events such as debris flows.
Within torrential watersheds, beside a relatively recent land-use planning, protective structures such as embankments, check-dams, sediment traps or bank protections, were established for years along streams, both in order to prevent triggering and limit potential destructive effects of phenomena in settlements and areas of economic activities [7]. Thus, there is a fundamental need to embed these two risk prevention strategies as they target the same finality of risk reduction. For instance, in Switzerland, land-use planning takes into account existing protective structures, assessing their effectiveness and establishing hazard maps according to them [8]. However, taking into account protective structures in land-use planning remains challenging. Their capacity must be guaranteed according to a defined and accepted hazard scenario which fit with PPR's requirements. Unless a general accepted recommendation consisting in preventing any developments behind those protections, published guidelines didn't provide clear directives on this aspect and practices widely differ following local feedbacks. Lievois \& Choznacki (2011) [9], from the Mountain Restauration Service (RTM) of the National Forestry Office (ONF), were able to put in light this diversity of practices concerning all types of protective structures usually set in mountains (against avalanches, rockfalls, landslides and torrents). This

\footnotetext{
${ }^{\mathrm{a}}$ Corresponding author: felix.philippe@irstea.fr
} 
enabled a relevant global overview and raised Government awareness about the necessity to reframe methodological guidelines.

For this purpose, a thorough analysis of PPR was recently carried out. Following, this paper targets two objectives. First, it aims to bring a detailed state of actual ways of integration of structural protections' effects in land-use planning, focusing only on torrential structures. Second, it deals with the level of traceability of this integration left into PPR, highlighting main missing points and proposing several enhancement axes. This traceability refers to several levels, from the general layout of documents composing PPR, to expert-decisions quality and methods used for effectiveness assessment of protective structures.

This study was carried out for operational purposes, under contract with the General Direction of Risk Prevention (DGPR). Resultant findings and recommendations will be integrated into Government's methodological guidelines for PPR establishment in torrential floods prone areas.

After giving some keys about research bounds and conceptual framing (part 2), this paper details methods and data used (part 3). Then, it introduces results from the analysis of French practices (part 4). Main limits and recommendations are presented in the $5^{\text {th }}$ part. Finally, it concludes on the operational use of those elements and gives some perspectives related to ongoing scientific developments.

\section{Research's bounds and conceptual framing}

\subsection{Torrential floods prone areas}

Unlike plain's floods, torrential floods are characterized by a high solid transport [10], result of great energy levels acquired by the flow over step slopes. This fundamental feature gives them a high destructive potential which can hardly be compared to plain's floods effects [11]. Knowing this overall distinction, torrential floods' solid transport features may vary according to a wide range of conditions $[12,13,14,15]$. For instance, in addition to rainfall event intensity and duration, geologic and geomorphologic settings can either lead to hyperconcentrated flows or debris flows [16]. Torrents, conveniently defined with slopes over a threshold of $6 \%$ $[13,17]$, are the most favorable streams for the triggering of such events. Torrential rivers, with bed slopes ranging from $1 \%$ to $6 \%$ [18], unless debris flows, can also lead to intense torrential events with bed-load transport as soon as the stream bed inclination is sufficiently high.

Hence, torrents and torrential rivers watersheds constitute the two main physical systems of interest when searching for torrential floods prone areas.

\subsection{Torrential structural mitigation measures}

Structural mitigation measures are set in order to reduce the existing risk to an accepted level of residual risk [19]. In mountainous areas, active and passive mitigation measures can be distinguished but French definition differs from German-language one for instance. For the latter, active means structural (e.g. all protective structures) and passive is used for nonstructural measures (e.g. land use planning) [20]. In France, active is used for protective measures (e.g. checkdams, forest) which aim at preventing torrential phenomena triggering over catchments areas changing their characteristics (intensity, occurrence and spatial extent). The word Passive concerns protective measures (e.g. sediment traps, dikes) which act on the phenomenon transfer before they reach settlements and areas of economic activities. It also concerns non-structural actions. Both French active and passive torrential protection structures were considered in this research. Were excluded all infrastructures not exclusively designed for a protective function, although they can strongly modify the propagation and the deposition of sediments (e.g. a short-section bridge). When having significant effects on torrential phenomena, protections designed for other phenomena were considered.

\subsection{PPR constitutive documents and main establishment steps}

According to the 1995 's law, each PPR has to gather specific constitutive documents:

- a hazard map, showing hazard level within specific areas delimited over the assessed perimeter (when several phenomena are considered over the same area, the hazard level displayed is always the most important one, without interaction between the different processes),

- a land-use planning map (the only regulatory document enforceable against third parties), showing land-use rules relevant according to areas delimited on the hazard map,

- a regulation document gathering all rules applicable within areas delimited on the land-use map,

- and a well-detailed report presenting the steps involved to draw the hazard and the land-use maps, including methods and tools used.

To be aware of the way that protective works' integration can differ from a plan to another, it is essential to detail the main PPR establishment steps.

First of all, phenomena likely to occur within the studied perimeter are identified and defined according to their intensity and likelihood of occurrence (or frequency). These parameters can be estimated through the consultation of past events, physical or numerical modeling or expert judgments.

The hazard map is then drawn using several hazard levels which depend on intensity and frequency of phenomena. Three degrees of hazard are generally used 
(high, moderate and low), with colors depending on local uses. White zones can also be defined when no hazard is identified or is not expected to lead to any consequences for people, buildings or economic activities.

Finally, the land-use map shows different levels of regulation on the basis of hazard levels and elements at risk over areas. Regulated zones are divided into two main categories:

- a red zone, where new projects are prohibited and existing buildings can be maintained without any enlargements and by fulfilling particular security requirements,

- a blue zone where projects can be allowed with respect of several restrictive conditions.

Specific rules applied over these regulated areas are listed in the regulation document.

The Figure 1 bellow gives a schematic overview of PPR establishment steps from natural phenomenon identification to the land-use regulatory zoning.

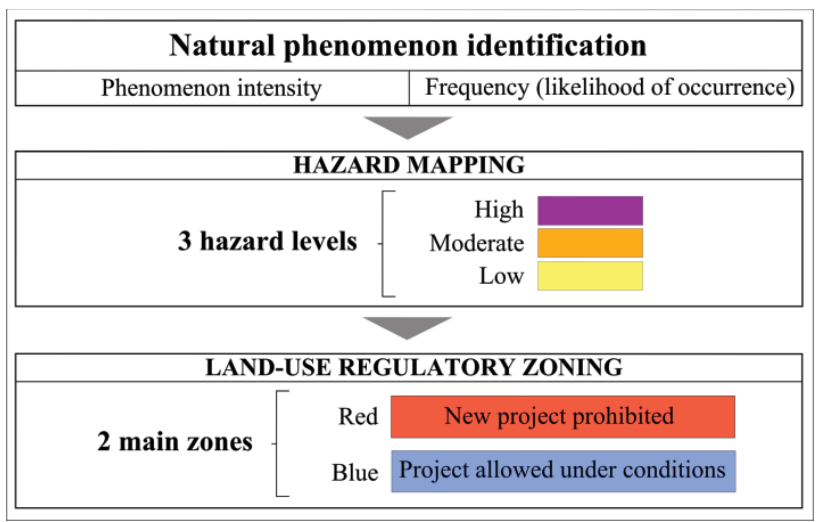

Figure 1. General simplified steps of PPR establishment from natural phenomenon identification to the regulatory zoning.

\section{Methods and data}

\subsection{PPR choice and collection}

The study focuses on the two main French mountainous areas: the Alps and the Pyrenees. These two massifs gather quantity of torrents' and torrential rivers' watersheds, as well as many torrential protective structures set and currently managed for a large part by agents from RTM services. These services exist within 11 departments that cover the whole Alps and Pyrenees massifs (Figure 2): Haute-Savoie (74), Savoie (73), Isère (38), Hautes-Alpes (05), Alpes-de-Haute-Provence (04), Alpes-Maritimes (06), Pyrénées-Orientales (66), Ariège (09), Haute-Garonne (31), Hautes-Pyrénées (65) and Pyrénées-Atlantiques (64).

\subsubsection{Choice of relevant risk prevention plans (PPR)}

PPR are prescribed for municipalities. The 11 abovementioned departments gather 4075 municipalities.
Therefore, some criteria were defined in order to select only municipalities with relevant approved PPR. Firstly, municipalities were sorted according to the Gaspar database $^{1}$ from the DGPR, which gathers information about plans (e.g. existence/absence, phenomena taken into account, approval date). From this, PPR taking into account "torrential floods" and approved after 2005 (it turned out that it was the most optimal date to get a satisfactory number of recent PPR), were selected. Secondly, two other criteria were applied. The first one allows excluding PPR established over plains' areas. In fact, the Gaspar database uses a definition of "torrential floods" which doesn't take into account solid transport, but only the short-time response of streams, which can be found over flat areas and not exclusively in mountains. The second and last of all criteria, deals with the confirmed presence of protective structures over PPR's study areas (information found after short analysis of documents and according to information from some RTM services). The resulting sample gathers 97 PPR that are potentially relevant to undertake the study (Figure 2).

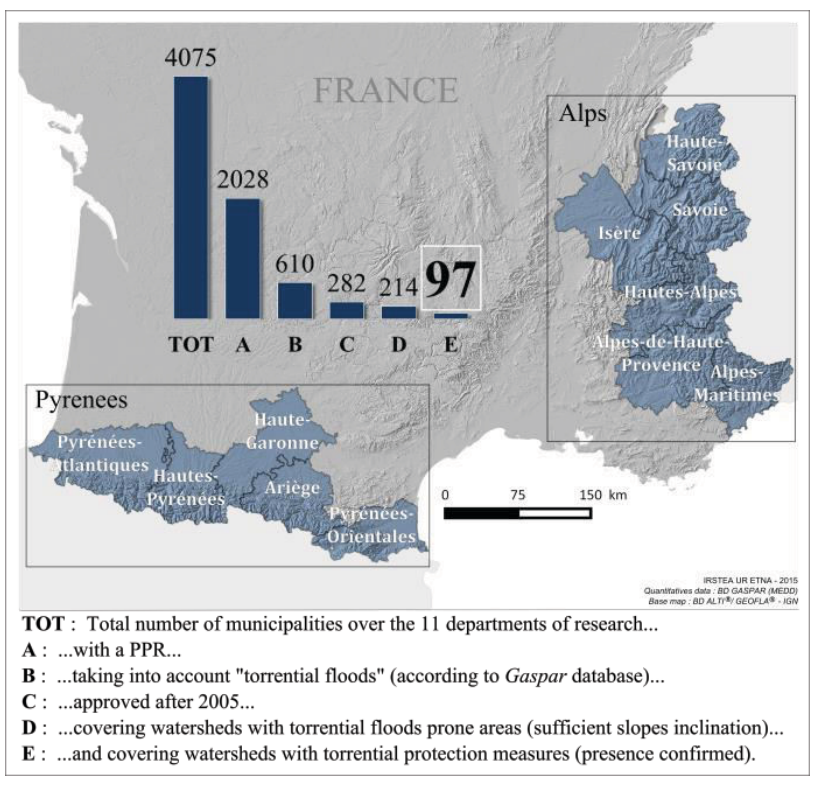

Figure 2. Criteria applied on Gaspar database (A, B, C), and additional ones $(\mathrm{D}, \mathrm{E})$, to get a relevant sample of PPR for the study over the 11 departments of interest.

\subsubsection{Availability of PPR documents}

Among this sample of 97 PPR, 53 were analyzed (55\%), according to documents' availability. In addition to torrential risks, all of these 53 PPR, except one, consider other mountain risks which are landslides, rock falls and snow avalanches.

Once approved, these PPR are of public interest and many of them were easily found on departmental services' web-platforms. The others were compiled thanks to the cooperation of land-use planning stakeholders, especially from departmental services of the MEDDE and the RTM.

\footnotetext{
${ }^{1}$ Aided Management of Administrative Procedures for Natural and technological risks (http://macommune.prim.net/gaspar/)
} 


\subsection{Extraction of PPR's data}

This study aims at highlighting methods/ways of torrential protection integrations within actual hazard and land-use zoning, as well as qualifying the quality of traceability of the process. To do this, several types of information were exhaustively extracted from the 53 selected PPR following strictly the same approach, so the comparison between them would be relevant.

Therefore, 304 protective civil engineering structures were counted as long as they were mentioned into documents. Most of them refer to individual structures (e.g. one check-dam), but some relates to protective devices (e.g. a series of check-dams set along a torrent channel). Even if counting individually each single structure would have made sense from a methodological point of view, that wasn't always possible according to PPR preciseness.

Then, corresponding information were kept and sorted into tables for qualitative and statistical analysis. Information collected ideally allow to know about:

- the structure's type (including the type of mitigation strategy, i.e. active or passive),

- the kind of torrential stream concerned (torrent or torrential river),

- the general principle of works' effects integration within hazard and land-use zoning,

- the real integration of works' effects within hazard and land-use zoning,

- the criteria and methods such as expert-based approaches, used to justify zoning choices according to effectiveness protective structures, considering dependability indicators, structural and functional criteria [21],

- the quality of registration and localization of protective structures (e.g. use of specific maps, tables).

Some information, although not directly relating to protection works, were also gathered as they remain essential for the global transparency of PPR, e.g. definitions of torrential phenomena used, methodologies used for hazard levels' definition as well as for hazard and land-use zoning.

\section{Integrating torrential protective structures within PPR: state of actual practices}

\subsection{General overview of practices over the Alps and the Pyrenees}

Among the 53 selected PPR, analyses reveal that 19 have been established taking into account one or several torrential protective works. That represents more than one third of the sample which is significant. For 5 departments over the 11 studied (code 04, 06, 09, 64 and 65), where information are missing, uncertainties remain concerning $7 \mathrm{PPR}$. As an example, in the Alpes-deHautes-Provence department (04), 3 PPR have been identified as taking into account protective works, whereas it is doubtful for 2 others (Table 1). That reveals traceability failing which will be presented later in this paper (see details in part 5).

\begin{tabular}{|c|c|c|c|c|c|c|}
\hline Massif & $\begin{array}{l}\text { Department } \\
\text { (Code) }\end{array}$ & $\begin{array}{l}{[1]} \\
\text { Number of } \\
\text { analyzed } \\
\text { PPR }\end{array}$ & $\begin{array}{l}{[2]} \\
\text { Nur } \\
\text { whe } \\
\text { seve } \\
\text { pro } \\
\text { are } \\
\text { acce }\end{array}$ & $\begin{array}{l}\text { ber of PPR } \\
\text { re one or } \\
\text { ral torrential } \\
\text { ective works } \\
\text { aken into } \\
\text { unt }\end{array}$ & Ratio & $2 / 1$ \\
\hline $\begin{array}{l}\text { Northern } \\
\text { Alps }\end{array}$ & 74 & 9 & 3 & & $33 \%$ & \\
\hline $\begin{array}{l}\text { Northern } \\
\text { Alps }\end{array}$ & 73 & 6 & 6 & & $100 \%$ & \\
\hline $\begin{array}{l}\text { Northern } \\
\text { Alps }\end{array}$ & 38 & 4 & 3 & & $75 \%$ & \\
\hline $\begin{array}{l}\text { Southern } \\
\text { Alps }\end{array}$ & 05 & 6 & 4 & & $67 \%$ & \\
\hline $\begin{array}{l}\text { Southern } \\
\text { Alps }\end{array}$ & 04 & 6 & 3 & to 5 & $50 \%$ & to $83 \%$ \\
\hline $\begin{array}{l}\text { Southern } \\
\text { Alps }\end{array}$ & 06 & 2 & 0 & to 1 & $0 \%$ & to $50 \%$ \\
\hline Pyrenees & 66 & 2 & 0 & & $0 \%$ & \\
\hline Pyrenees & 09 & 6 & 0 & to 2 & $0 \%$ & to $33 \%$ \\
\hline Pyrenees & 31 & 5 & 0 & & $0 \%$ & \\
\hline Pyrenees & 65 & 3 & 0 & to 1 & $0 \%$ & to $33 \%$ \\
\hline Pyrenees & 64 & 4 & $\mathbf{0}$ & to 1 & $0 \%$ & to $25 \%$ \\
\hline \multicolumn{2}{|l|}{ Total } & 53 & 19 & to 26 & $36 \%$ & to $49 \%$ \\
\hline
\end{tabular}

Table 1. Number and percentage of PPR established taking into account one or several protective works.

According to this sample, all 19 PPR taking into account protection works were approved over municipalities from the Alps. Even if uncertainties remain for 4 PPR in the Pyrenees, this brief overview reveals a spatial repartition: a torrential protection structure is more likely to be considered in PPR from the Alps than from the Pyrenees.

\subsection{Types of works taken into account}

Within this 19 PPR, effects of 54 protective works were taken into account under a variety of forms that will be detailed afterwards (see part 4.3). Most of these works are torrential dikes and also bank protections, whereas other structures such as sediment traps or check-dams are less integrated (Table 2).

\begin{tabular}{lcc}
\hline $\begin{array}{l}\text { Types of works taken into account for PPR } \\
\text { establishment }\end{array}$ & $\begin{array}{c}\text { Number of } \\
\text { works }\end{array}$ & $\begin{array}{c}\text { \% of } \\
\text { total }\end{array}$ \\
\hline Torrential dike & 27 & $50 \%$ \\
Bank protection & 11 & $20 \%$ \\
Sediment trap & 4 & $7 \%$ \\
Check-dam & 4 & $7 \%$ \\
$\begin{array}{l}\text { Correction and recalibration works aiming at } \\
\text { modifying stream's longitudinal and transversal } \\
\text { profile }\end{array}$ & 4 & $7 \%$ \\
Torrential flood discharge channel & 1 & $2 \%$ \\
Torrent backfill barrier & 1 & $2 \%$ \\
Landslide barrier & 1 & $2 \%$ \\
Torrent drainage channel & 1 & $2 \%$ \\
\hline Total & $\mathbf{5 4}$ & $\mathbf{1 0 0 \%}$ \\
\hline Table 2. Types and number
\end{tabular}

Table 2. Types and number of works taken into account in the establishment of 19 PPR. 
In accordance to uncertainties previously highlighted (see part 4.1), several works may have been taken into account in plans for which no sufficient information have been found. Those works are not presented in this paper.

\subsection{Integration of protection works' effects and PPR establishment steps}

The way the 54 protection works (Table 2) are taken into account differs in a wide variety according to municipalities. Knowing PPR establishment steps (see part 2.3) and the Swiss process [8], expectations would have been to observe works' effects integration from, at least, the definition of hazard levels, allowing to draw the hazard map. However, it appears that practices do not always follow the logical methodological pathway leading to the final regulatory zoning and the applicable land-use rules. The Figure 3 shows in detail these practices, for the Alps only. Practices vary from a department to another and also inside them. At all, 10 different ways of integration were encountered in the 19 PPR for which no doubt exist concerning the fact that one or several torrential protections were taken into account. In some cases, several ways of integration (relating to several protective structures) were encountered in the same PPR.

The most common way (9 cases encountered) consists in taking into account effects of protections when mapping hazards levels, and then to draw regulatory zones which fit with them. This method was used in PPR from Haute-Savoie, Isère, Hautes-Alpes and the Alpes-
de-Haute-Provence. The other most used method can be observed only in Savoie, where a singular methodology for the design of hazard maps was put in place. In this department, hazard levels are assessed according to several classes of frequency and intensity which are crossed over a matrix. This allows to get a comprehensive link between phenomena characteristics and related hazard levels. Effects of protections are clearly assumed displaying intensity and frequency classes with and without protection for each concerned areas. In most of the cases (6 over 8), both frequency and intensity of phenomena are modified with consequences on hazard and land-use regulatory zoning. In the two other situations, only frequency is modified; in one case it leads to modify hazard and regulatory zoning, and for the other one it doesn't because change in frequency class remains not sufficient to make the hazard level go to the lower step.

Unlike previous ones, other methods skip one or several parts of the logical PPR establishment process. The first and most frequent one consists in modifying only the regulatory zoning, without any change concerning hazard levels. In one PPR approved in the Hautes-Alpes, the modification of the regulatory zoning may relates to a modification of the hazard zoning, but all collected information left in this PPR do not give any certainty on this. The second method integrates effects of protective structures only at the step of hazard mapping. Here again, uncertainties remain about a possible influence on the regulatory zoning for one PPR from the Alpes-de-Haute-Provence. A third and last practice was

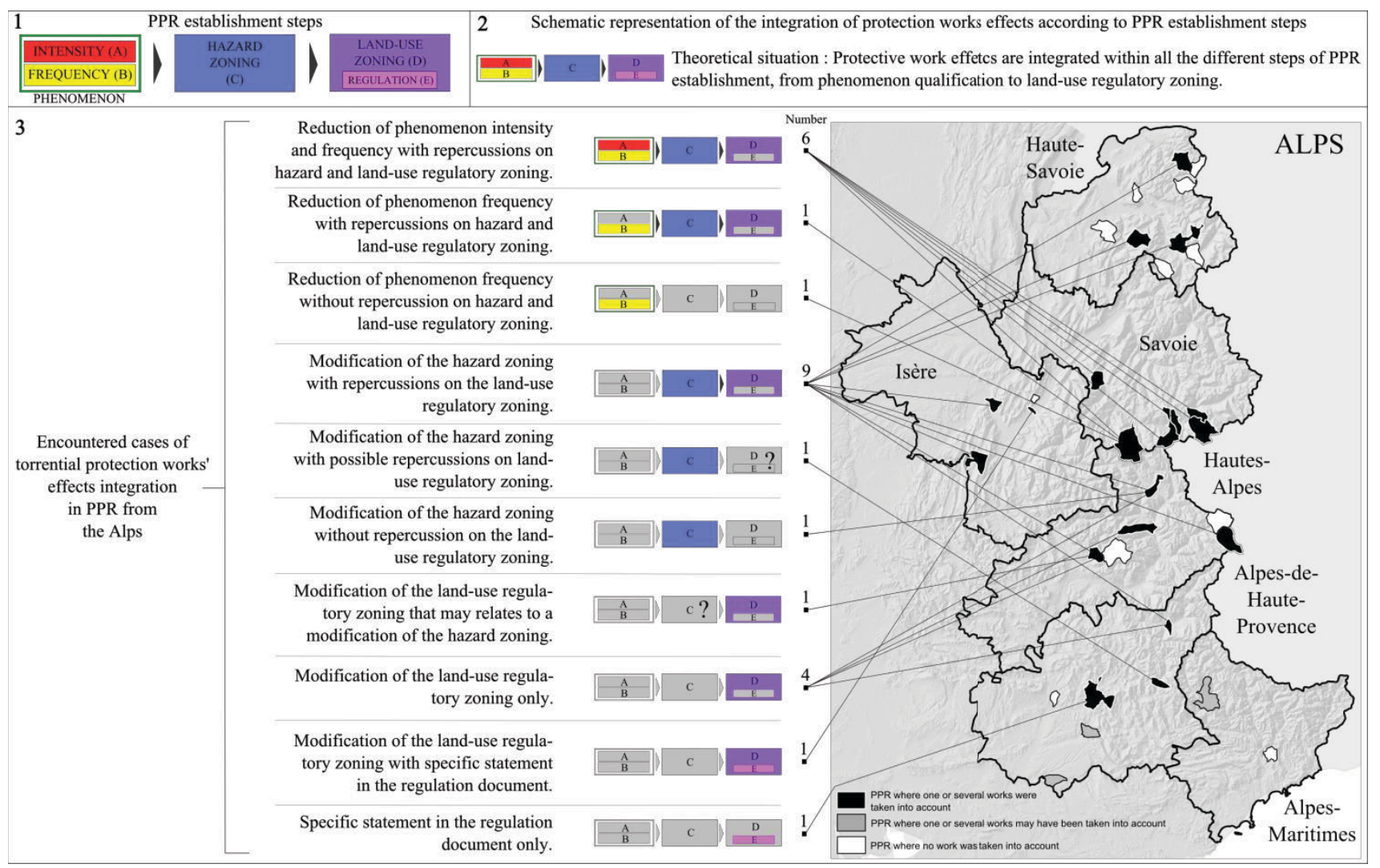

Figure 3. Spatial repartition of the different ways used to take into account torrential protections in PPR assessed over the Alps according to the PPR establishment steps. 
highlighted in a PPR from the Alpes-de-Haute-Provence, where hazard and regulatory zoning aren't modified but specific mentions concerning a protection exist within regulation.

\subsection{Integration according to type of works}

The most common way of torrential protective works integration into PPR consists in taking into account their effect directly to draw the hazard and the regulatory zoning (see part 4.3). Most of the time, this practice applies with torrential dikes. The latter also prevails when only the regulatory zoning is influenced. In the case where protection's effect is taken into account since the hazard level assessment (frequency and intensity), bank protections as well as check-dams and sediment traps are more represented (Figure 4).

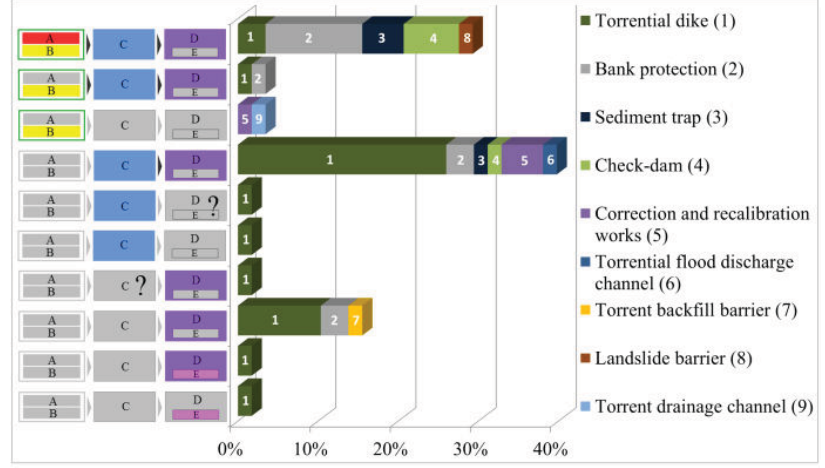

Figure 4. Relation between the 10 ways used to take into account protection works in PPR and types of protections.

\subsection{Study cases}

Examples are presented for two relevant cases of torrential protections' effects integration in PPR establishment. Both examples show integration from hazard mapping with different methods.

\subsubsection{Case 1: PPR of the municipality of Bramans (Savoie), adopted in 2014 [22]}

As all PPR from Savoie, a frequency-intensity matrix is used in this first case to define hazard levels over delimited areas. Classes of intensity go from 0 to 3 , with: 0-negligible; 1-low; 2-moderate; 3-high and $3^{+}-$ exceptional. Classes of frequency go from 1 to 6 with: $1-$ potential (no sign of any past event); 2 -rare ( $\mathrm{T} \geq 100$ yrs.); 3-not frequent $\left(50<\mathrm{T}<100 \mathrm{yrs}^{2}\right.$.); 4-moderately frequent $(20<\mathrm{T}<50 \mathrm{yrs}$. $) ; 5-$ frequent $(5<\mathrm{T}<20 \mathrm{yrs}$. $)$ and 6-very frequent $(0<\mathrm{T}<5$ yrs. $)$. A truth table helps assessing the hazard level knowing intensity and frequency ones, e.g. an intensity of 2-moderate and a frequency of 2-rare give a hazard level of moderate over a 4 levels scale (none, low, moderate, high). Each zone is then qualified with an alphanumeric code identifying the phenomenon and the related frequency and intensity levels with and without taking into account effects of protective structures. The reference scenario used to

2 " $\mathrm{T}$ " is the return period expressed in years (yrs.). The more $\mathrm{T}$ is large, the more the frequency is low. establish the hazard level is underlined (Figure 5). This method, denoted as $C 2 P N$, can be considered as a good example of traceability of hazard and risk assessment.

$\begin{aligned} & \text { Phenomenon: } \\ & \text { torrential flood }\end{aligned} \mid \begin{aligned} & \text { Not taking into account protections, the } \\ & \text { phenomenon has a high intensity and is } \\ & \text { very frequent. }\end{aligned}$

Figure 5. Example of alphanumeric qualification of hazard level according to the method used in Savoie.

The village of Bramans is built on the alluvial fan of the Ambin torrent. A 150 meters long torrential dike was set up on the right bank of this torrent in order to limit overflowing over settlements areas located in the downstream part of its alluvial fan. Taking into account dike's effect, the hazard level remains high up to 100 meters away behind it (Figure 6).

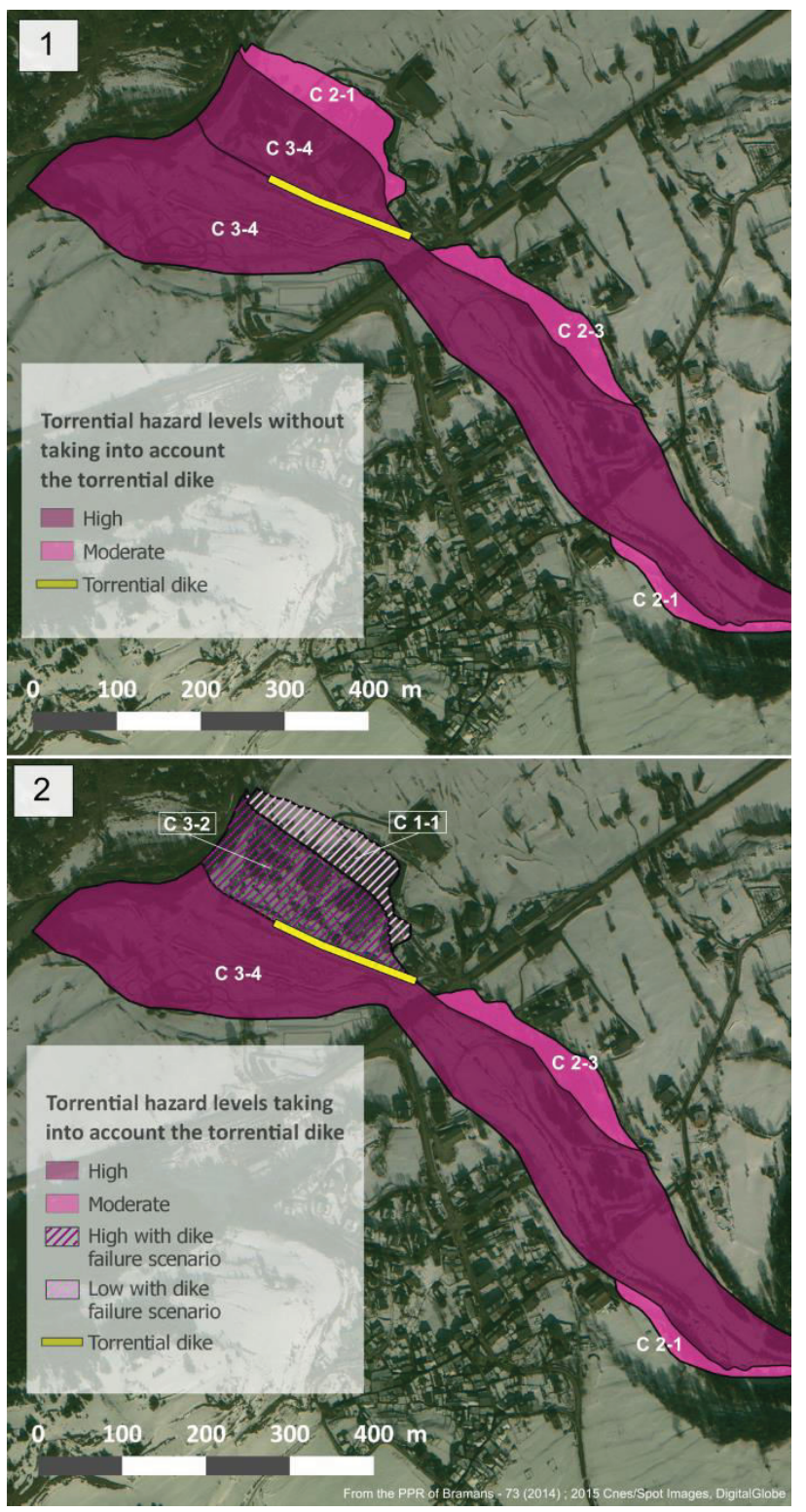

Figure 6. Torrential hazard levels without taking into the torrential dike (1) and taking it into account (2) in the PPR of Bramans over both sides of the Ambin torrent. 
Indeed, although the frequency goes from class 4moderately frequent without the protection, to class 2rare with the mitigation effect, phenomenon intensity remains 3-high in both cases: the hazard levels cannot get lower. However, hazard is reduced on the further zone (between 100 and 150 meters away from the dike's foot) from moderate to low. Within it, the intensity goes from 2-moderate to 1-low, while frequency remains 1potential taking or not taking into account the dike (Figure 6). Hazard mapping also shows the possibility of dike's failure using hatched symbols (Figure 6.2).

As a consequence of this hazard mapping, regulatory zoning is not modified concerning the 100 meters wide zone behind the dike, which remains in a red color in any cases, corresponding to high hazard level. Within this zone, new projects are prohibited according to the high hazard level. However, binding rules are more flexible over the further zone identified behind the dike (between 100 and 150 meters away), due to the reduced flood potential intensity. There, projects are allowed under slight conditions for a low hazard level whereas rules would have been more restrictive for a moderate hazard level, without considering dike's effect.

\subsubsection{Case 2: PPR of the municipality of La Salle les Alpes (Hautes-Alpes), adopted in 2009 [23]}

This other study case also deals with the consideration of dike's effect to draw both hazard and regulatory zoning. The context is similar, knowing that it's about preventing torrent overflowing over an inhabited zone located on the downstream part of an alluvial fan. Here, two contiguous structures were set up along the left bank of the so-called torrent of La Salle: a dike made of concrete and a torrent backfill barrier. The backfill barrier constitutes the upstream extension of the dike and it doesn't strictly follows the torrent left-bank line, but leaves a space (up to 70 meters) between its foot and the stream bed (Figure 7). This allows a wider hydraulic capacity of the torrent in case of intense floods that may not be contained by the original channel. Unlike for the previous case, this PPR uses neither frequency-intensity matrix nor code allowing identifying hazard level with and without taking into account effects of protections. However, the detailed report gives sufficient explanations. Then, due to protections, the area located behind (surrounded by a solid white line) is characterized by a low hazard level (T1), which would have been moderate (T2) otherwise. From the side of the regulatory zoning, it's a blue zone where projects can be allowed under conditions (Figure 7.2).

\section{Traceability issues and potential improvements for protections' effects integration into PPR}

On the basis of PPR's analysis feedbacks, several points of discussion are developed hereafter. They aim to highlight main issues and to propose some recommendations supported by best actual practices, in order to strive toward an homogenization of practices for a better traceability of PPR.

\subsection{A common typology of protective structures and torrential phenomena}

Take into account torrent protective works when delimitating hazard and regulatory zoning implies to state on strict definitions of these protections. By definition, it must be understood that functions of protective structures are well identified. Feedbacks of the present analysis reveal some confusion in protection works' identification, leading to missing readability of their functions and potential effects. The most significant case comes from a PPR of Savoie, where the torrential flood hazard level goes from high to negligible after considering bank protections' effect on the left bank of a torrent. This reduction is justified by the capacity of these "bank protections" to limit torrent overflowing for the reference event, that is, a debris flow able to transport roughly $100000 \mathrm{~m}^{3}$ for $70000 \mathrm{~m}^{3}$ of materials deposition. In this particular case, bank protections set along the torrent are rather dikes, or torrent backfill barriers, that go up to the natural level of the ground. In fact, bank protections, by definition, allow limiting bank erosion and can't prevent
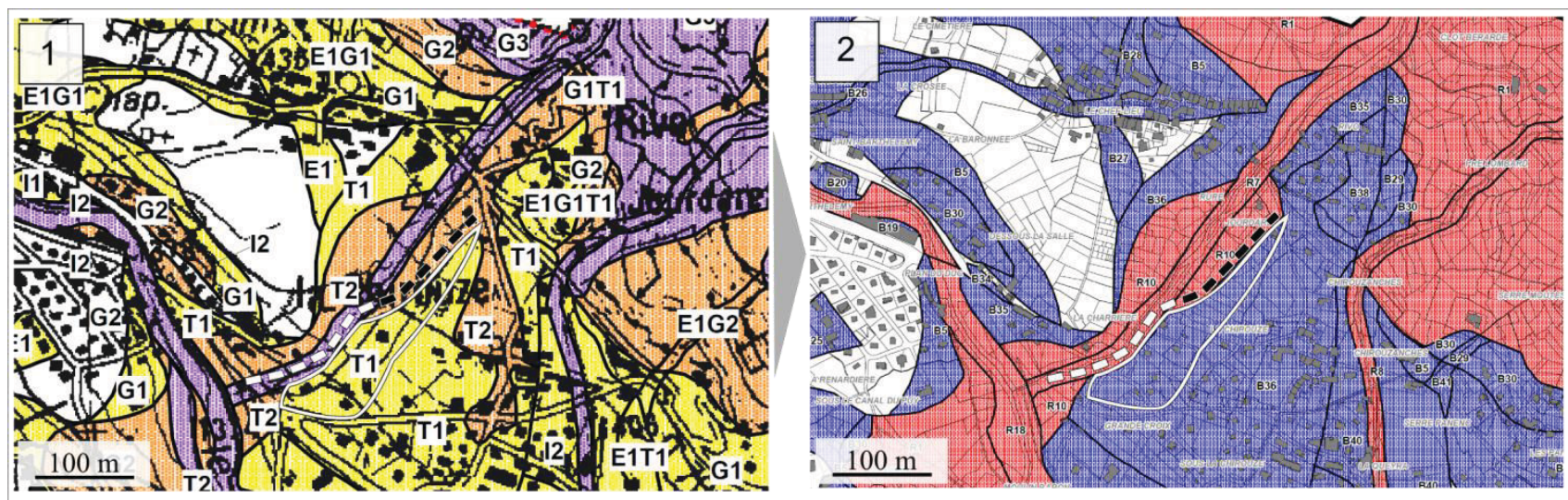

Figure 7. Hazard (1) and land-use regulatory zoning (2) from the PPR of La-Salle-les-Alpes. 
any overflowing as their highest level remains under or equal to the natural level of the ground.

Beyond this wrong semantic distinction of bank protections, the formalization of torrential protection functions for each different type of structure acting for the mitigation of torrential risks is far from obvious. Indeed, the diversity of structures and criteria that may be used to define them are almost endless. Moreover, according to the historical context in which the works were carried out, functions assigned to them may evolve; this is especially true for torrent check-dams that have been set up in Alpine valleys from the nineteenth century [24].

To date, several works were initiated to try to bring solid bases to strive towards an unified torrent protection typology. In France, the Rehabilitation of Mountainous Lands department put in place a database where are recorded protection works set over national perimeters within the 11 studied mountain departments. This database gathers many kinds of information on works including their functions. Focusing on sediment traps, work from Piton \& Recking (2015) [25], makes a relevant review of the literature concerning the function and the design of these particular structures. In Austria, work from Hübl and Suda (2008) [26] gives an overview of debris flow structural mitigation measures (including debris flow breakers, check-dams, debris flow net barriers etc.) with regard to their functions.

Current ongoing works are of great interest and start to pave the way for an homogenization of intellectual though regarding the definition of torrent protection works functions. Then, a national official typology could be drawn and used as a guideline to nominate protection and identified without any confusion and misunderstanding their function.

The same effort could be done for the proposition of solid definitions of torrential phenomena, which allow defining functions of protective structures by solving the question: What's the nature of the event the structure will have to face? Between PPR, main criteria used for defining torrential phenomena widely differ: high streambed level variations, bank scouring, characteristics of the flow (i.e. one or two phases), irregularity of channel pathway over the alluvial fan and time response of waters. One PPR even uses a larger definition of torrential phenomena involving floods without high solid transport, which relate to radically different processes and threats. This diversity reveals the complexity of factors that have to be taken into account when considering torrential phenomena. Solving the issues of a common definition that gathers all essential processes potentially involved during a torrential event could help, but that remains definitely challenging.

\subsection{From structure registration to specification of its potential effect as soon as the hazard level assessment step}

This second point of discussion deals with the necessity to keep a strict methodological logic when considering effects of protections for drawing hazard and regulatory zoning. Unlike study cases above presented (see part 4.5), practice consisting in taking into account protection only for the regulatory zoning is common (see part 4.3). In such cases, regulatory zoning choices are not fully justified and illustrated through the hazard map. Furthermore, serious confusions can appear when inconsistencies exist between both zonings (Figure 8). This practice was made possible because of guidelines allowing defining some specific adaptions in regulations concerning constructability behind protection works, while keep arguing for the total transparency of works' effects when drawing hazard zones. Recently published guidelines focusing on avalanche risk, started to change the overall orientation of recommendations on this issue. For the first time, the necessity to consider protection works' effects from the hazard zoning step is stated. As in Swiss [8], or in Savoie, this goes even further as the mapping of two hazard maps (one taking into account protections and another not) is recommended in order to keep as much as possible a good traceability of zoning approach. Indeed, drawing two hazard maps allows visualizing concretely protective structures' effects.

Following last recommendations, guidelines for the establishment of PPR into torrential flood prone areas would also advocate such methodology. Effects of protections could then be more comprehensible by readers, especially lay persons, leading to a better acceptance of the risk and the related land-use regulations.

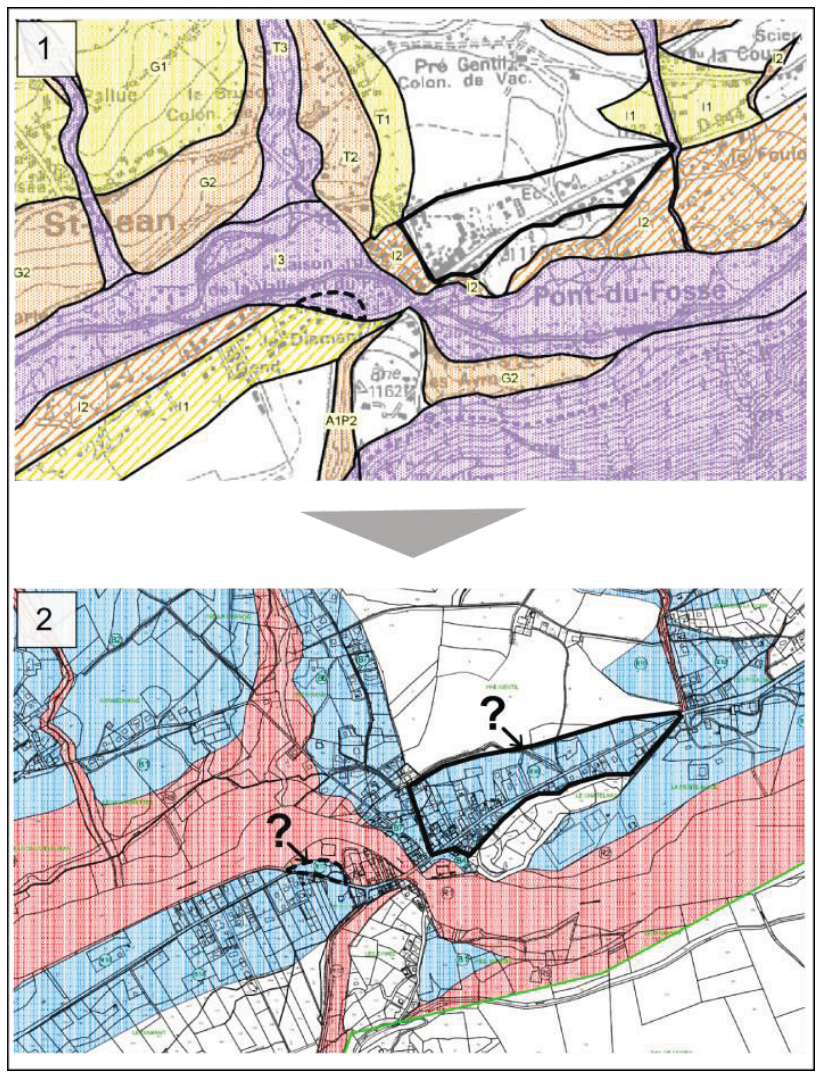

Figure 8. Ambiguity between hazard (1) and the related regulatory zoning (2) in a center of a municipality from the Hautes-Alpes department. 
Even using two hazard maps, effects of protection structures could remain poorly readable if they can't be clearly located. Lack of information on structural protections taken into account for hazard or regulatory zoning is common according to the 53 analyzed PPR. Indeed, protection works are seldom located and the use of inventory tables is not the main way in use (Figure 9).

According to the context and the number of structural protections set up over PPR's perimeter, such inventory could take a lot of time and involve extra costs that may not be supported by stakeholders. However, good examples can be found in some PPR where a significant attention was paid to give as much information as possible about protective structures. The best example comes from Haute-Savoie with a PPR inventorying all protective structures within tables gathering information like the kind of structure (e.g. shape, dimensions and materials), the type of mitigation strategy (active or passive) and the general structural state with attached pictures. Each individual structure is also clearly located on specific maps. In PPR from Savoie, unless having proper inventory tables, protection works are located directly over hazard maps, allowing a good match between hazard level reductions and related structures. Feedbacks from these PPR would be used in order to build a relevant methodology of protection works' inventory, which remains of great interest especially when considering their effects.

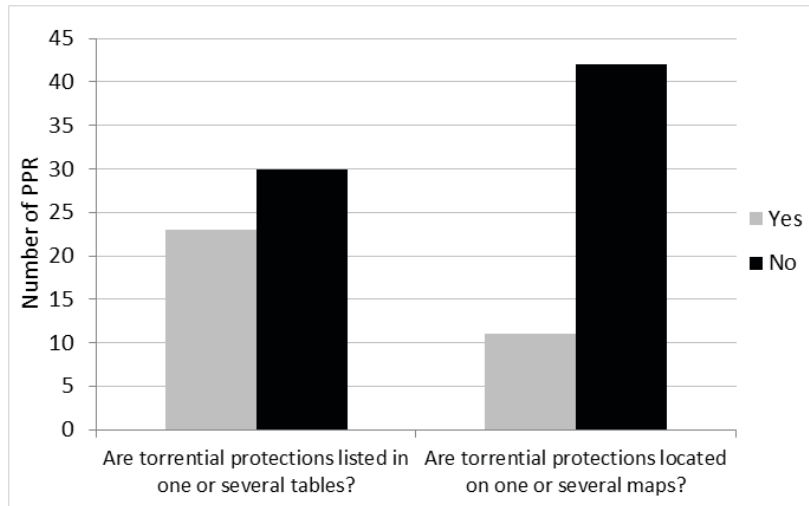

Figure 9. Number of PPR using tables and/or maps for torrent protection works' inventory.

\subsection{Displaying principles of protection works' integration as traceability of the general zoning approach}

An essential element of traceability in terms of protection works' integration within PPR belongs to the principle displayed. Indeed, it reveals the general approach that has been theoretically followed for the PPR establishment. Those principles are often derived from national guidelines. They are thus very general and without lots indications. Uncertainty about steps that can be actually involved when taking or not taking into account protections are often left, and only one principle refers to the possible integration under conditions of protections for both hazard and regulatory zoning (Table 3).
No principle announced.

$30 \%$

Works can be taken into account under conditions.

$26 \%$

Works must not be taken into account for hazard zoning, except in very specific cases.

$15 \%$

Works must not be taken into account for hazard zoning.

$14 \%$

Works can be taken into account under conditions for hazard and land-use regulatory zoning.

$10 \%$

Aggravating effect of structural protections can be taken into account for hazard zoning.

$3 \%$

Works can be taken into account under conditions for land-use regulatory zoning.

Total

$100 \%$

Table 3. Principles of integration of torrent protection structures announced in the 53 PPR's detailed reports.

Those general principles are often not relevant according to the different types of protection structures, as well as local contexts were multiple and complex physical, social and economic factors overlap within restricted areas. Although some PPR's authors try to give more readability of the detailed report, by giving more details of their zoning approach with regard to protection works' effects integration, contradictions exist in some PPR between principles and real practices. Beside the fact of being confusing, such contradiction may lead to inconsistency of PPR documents once they are used to solve litigations.

The zoning approach would become more readable with a general principle of protection works' effects integration, followed by particular adaptions according to local contexts and especially the types of structures.

\subsection{The need to justify the reference scenario}

To date, PPR's hazard zoning are based on theoretical event having a return period of about 100 years, except if an event of higher intensity is known. Such definition of reference scenario match easily in the context of plain's floods, where probabilities can be drawn according to the well-known mechanisms defined through the clear water hydraulics. However, in torrential context, the complex response of watersheds which doesn't follow solid patterns, such probabilities can hardly be estimated. Moreover, knowledge on torrential mechanisms, leading to some extreme events like debris flows, remains limited. Time allowed to PPR's establishment doesn't allow undertaking long and detailed hydrological studies which would be necessary to estimate reference event characteristics with a satisfactory degree of accuracy.

Knowing all these limits, it seems essential to try to define as precise as possible the characteristics of the reference scenario that have been drawn, and to keep a 
traceability of the method used, especially when taking into account protection structures.

Within PPR taking into account protections, it appears that these scenarios are, in numerous cases, not sufficiently detailed. Assumptions on event intensity are seldom presented and methodology used not clearly given. Regarding PPR not taking into account torrential structural protection, reference scenarios are never justified. In this case, two assumptions can be done:

- a reference scenario not taking into account protection has been established,

- no particular reference scenario has been drawn and the protection works were simply ignored.

In the first case, the reference scenario can only be theoretical, i.e. without comparison to any past event. The methodological lock is especially true with torrent checkdams, which deeply modify watershed processes. In such cases, it seems ambitious and even hazardous to try to get a relevant picture of the situation as it was before checkdam setting years ago. In any cases, clearness could be easily gained into PPR's reports by justifying choices and assumptions inherent to such complex contexts.

\subsection{Towards a decision-aid method for taking into account protection works into PPR}

Taking into account protective structures is ideally based on the assessment of their effectiveness. Nevertheless, effectiveness remains an unclear concept and its assessment is thus not well formalized, especially in torrential context [27].

Effectiveness of a structure can be assessed according to several criteria referring to its capacity and its dependability [21]. The capacity of a structure refers to technical characteristics measurable and associated to a function. Functional abilities of a structure depends on many factors like the design, the localisation, as well as the structural state, dependent to external and internal stability factors, as well as to materials alteration. Dependability, a concept borrowed from industrial context, is classically assessed along four attributes:

- Reliability: ability of a system to fulfill functions specified during a reference period (operational life of the system).

- Availability: ability of the system to fulfil its function at a particular point in time. This refers to the ability to maintain its operational functioning. E.g. after an event a dike broke down, it must be repaired quickly to be operational for the next potential event.

- Maintainability: ability to detect partial or total system's failures and fix them to bring it back to its operational functioning. This refers to the general maintenance conditions of protection works.

- Safety: absence of catastrophic consequences on the users and the environment. This relates to the possibility for a protection structure to lead to higher hazard intensity.

From expert opinions synthesized in the different PPR's detailed reports, were extracted effectiveness criteria used, associated with each protection structure identified. It has been shown that such criteria remain poorly used, except those referring to functional capacity of structures (Figure 10). Aspects related to the structural capacity and dependability are thus potentially less considered when assessing the effectiveness of protective structures. Therefore, effectiveness of protective structures can't be fully known as all essential criteria allowing assessing it aren't used. Besides this fact, the analysis also helps to highlight that criteria are never explicitly presented, but only mentioned and often implicitly, leading to missing traceability.

In order to guide expert evaluation, a working group worked on the development of a decision-aid method allowing to state on the possible integration of a structure for PPR zoning, taking into account structural, functional and dependability criteria. Recent developments also

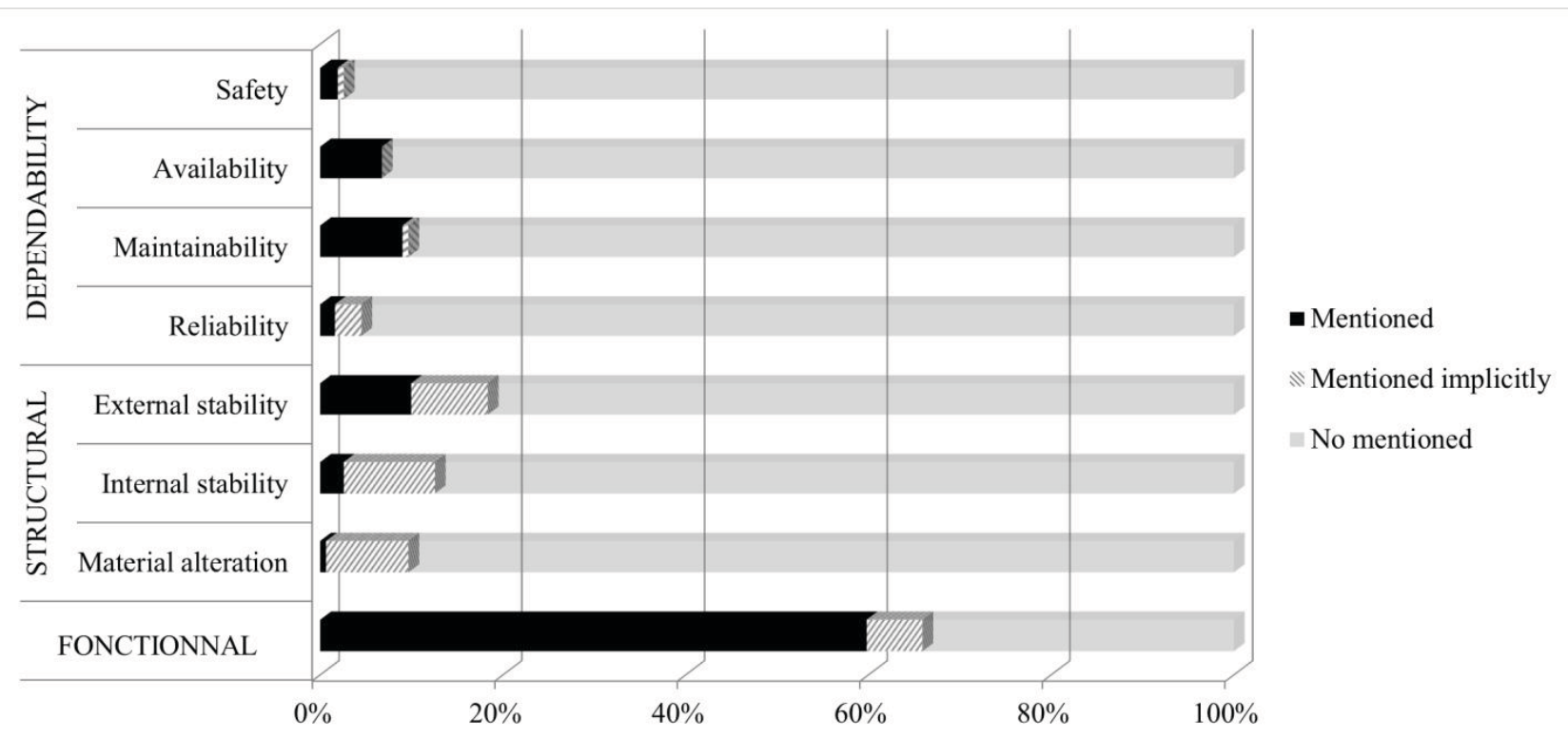

Figure 10. Percentage of effectiveness criteria associated to torrential protection structures mentioned in the 53 PPR's detailed reports analyzed. 
proposed new framework to assess protective works effectiveness considering structural, functional and economic features [28].

Those methods remain under formalization but start to give the way for a better traceability of expert approaches in the matter.

From the above, logical expert reasoning could follow a common logical structure.

An example could be:

i) Accepting that the general principle is not to take into account torrential protective structures for hazard and land-use mapping, the first decision problem relates to the level of potential exception to this general principle, for each type of structures and according to the method being developed based on functional, structural and dependability factors.

ii) Once it is generally decided that the studied kind of protective structure can be taken into account in the PPR establishment, it is needed to assess its capacity with regard to the chosen reference scenario, which thus need to be well defined. This also implies precise knowledge about protection work e.g. its function and the design calculation assumptions. Effectiveness criteria which would have been used in the first step would now ideally need deeper investigations in order to assess effect of the structure at each geographical point of interest for PPR's zoning.

iii) Once evaluated, effect is integrated as soon as the hazard zoning step and ideally displayed using a hazard map showing the difference between a situation free of protection and the reality.

\section{Synthesis and perspectives}

The first objective of this paper was to give an overview of actual practices in terms of torrential protection structures integration within land-use planning. Although being an important issue with regard to the risk mitigation in mountains valley, it remains under slight supervision from the French Government. As a result, a wide diversity of practices was developed according to local feedbacks and specific contexts. By analyzing recent Risk Prevention Plans over the Alps and the Pyrenees, those practices have been put in light with particular attention paid on the zoning steps involved when taking into account protection works, as well as on the type of protection taken into account.

A second objective was to highlight main points of enhancement concerning traceability of zoning approaches when taking into account torrent protection works. They have been pointed out from information collected. Discussions help striving toward a homogenization of practices in a context of the coming PPR's guide for torrential floods prone areas.

When speaking of traceability, complexity comes from the fact that different nested levels have to be considered. Main points identified refer to the need to:
- state on common definitions of torrential protections structures with regard to their functions, as well as on torrential phenomena, multiple and complex;

- take into account protection from the hazard mapping step, following the logical PPR establishment steps;

- visualize protection works' effects by using two hazard maps like is already done in Switzerland and in one department in France;

- visualize the precise location of protective structures for an easy match with hazard and land-use mapping;

- justify the chosen reference scenario in complex hydro-geomorphological contexts;

- draw a common effectiveness assessment method suitable for torrential protection works and that can take part of the overall expert approaches when taking into account structural protections into PPR.

To date, the ideal PPR, giving an optimal traceability of protection works' effects integration at each discussed level does not exist, because of time and funds allowed for their constitution. Methodological locks exist, especially regarding the definition of hazard scenario not taking into account structural protections. Huge progresses still need to be done to bring a relevant and complete methodology for protection works' effectiveness assessment. Nevertheless, ongoing works in the matter are promising and enhancements will come from embedded approaches from research and operational sides. Interoperability between actors is another huge subject of investigation; it started to rise in avalanche context [29].

The analysis of constructability conditions downstream protection structures remains an important issue. This work gives only a factual contribution on the state of practices; it doesn't prejudge the regulatory statement that would likely be retained or not in particular situations.

\section{Acknowledgments}

This study was funded by Irstea and the French Environment Ministry. Authors acknowledge partners from departmental services and from RTM for their availability to give us needed documents.

\section{References}

1. Peltier A. (2008). La cartographie réglementaire des risques naturels en Suisse, en Italie et en France. $L a$ mise en carte des risques naturels, Diversité des approches, Montpellier, Presses Universitaires de la Méditerranée, Géorisques, $\mathbf{n}^{\circ}$ 2, pp. 61-67. [In French].

2. Beck E. (2006). Approche multi-risques en milieu urbain - Le cas des risques sismique et technologiques dans l'agglomération de Mulhouse (Haut-Rhin). PhD Thesis. University Strasbourg I (Louis Pasteur), 283 p. [In French].

3. Ministry of territorial planning and environment, ministry of equipment, transport and housing. 
(1997). Plans de prévention des risques naturels prévisibles (PPR): Guide général, La Documentation française, 76 p. [In French].

4. Ministry of territorial planning and environment, Ministry of equipment, transport and housing. (1999). Plans de prévention des risques naturels prévisibles de mouvement de terrain: Guide méthodologique, La Documentation française, $72 \mathrm{p}$. [In French].

5. Ministry of territorial planning and environment, Ministry of equipment, transport and housing. (1999). Plans de prévention des risques naturels d'inondation: Guide méthodologique, La Documentation française, $126 \mathrm{p}$. [In French].

6. Ministry of ecology, sustainable development and energy (2015). Plan de prévention des risques naturels d'avalanche: Guide méthodologique, General Direction of Risk Prevention, 103 p. [In French].

7. Brugnot C. and Cassayre Y. (2002). De la politique française de restauration des terrains en montagne à la prévention des risques naturels. In Les pouvoirs publics face aux risques naturels dans l'histoire, pp. 261-272. [In French].

8. Margreth S. and Romang H. (2010). Effectiveness of mitigation measures against natural hazards. Cold Regions Science and Technology, 64(2), pp. 199207.

9. Liévois J. and Choznacki E. (2011). Enquête sur la place donnée aux ouvrages de prévention / protection dans les PPR approuvés pour lesquels les services RTM sont intervenus. Service de restauration des terrains de montagne (RTM), $11 \mathrm{p}$. [In French].

10. Meunier M. (1994). Les progrès de la connaissance et les méthodes d'étude des phénomènes torrentiels. La Houille Blanche, 3, pp. 25-31. [In French].

11. Gavrilovic Z., Stefanovic M., Milovanovic I., Cotric J. and Milojevic M. (2008). Torrent Classification Base of Rational Management of Erosive Regions, Institute for the Development of Water Resources, 9 p.

12. Aulitzky H. (1982). Preliminary two-fold classification of torrents. Mitt. Forstl. BundesVersuchsanst. Wien, 144, pp. 243-256.

13. Meunier M. (1991). Eléments d'hydraulique torrentielle. CEMAGREF, Etud. Sér. Montagne 1, pp. 1-278. [In French].

14. Blair T.C. and McPherson J.G. (1994). Alluvial fans and their natural distinction from rivers based on morphology, hydraulic processes, sedimentary processes, and facies assemblages. J. Sediment. Res. A64(3), pp. 450-489.

15. Pierson T. C. (2005). Hyperconcentrated flow transitional process between water flow and debris flow. Chapter 8 in Jakob, Matthias, and Hungr, Oldrich (eds), Debris-flow Hazards and Related Phenomena: Springer/Praxis, Chichester, UK, pp. 159-202.

16. Koulinski, V. (1993). Etude de la formation d'un lit torrentiel par confrontation d'essais sur modèle réduit et d'observations de terrain. $\mathrm{PhD}$ Thesis.
University Joseph Fourier - Grenoble I, pp. 17-18. [In French].

17. Tacnet J-M. (2009). Prise en compte de l'incertitude dans l'expertise des risques naturels en montagne par analyse multicritères et fusion d'information. Environmental Sciences. Ecole Nationale Supérieure des Mines de Saint-Etienne. [In French].

18. Ancey C. (2001). Debris flows and related phenomena. In Geomorphological fluid mechanics, N.J. Balmforth and A. Provenzale (Eds.): LNP 582, pp. 528-547.

19. Hübl J., Strauss A., Holub M. and Suda J. (2005). Structural mitigation measures. In Proceedings zum 3rd Probabilistic Workshop: Technical Systems + Natural Hazards, 12 p.

20. Zollinger F. (1985). Debris detention basins in the European Alps, International Symposium on Erosion, Debris Flow and Disaster Prevention, Tsukuba, Japan, pp. 433-438.

21. Tacnet J-M, Curt C., Rey B. and Richard D. (2012). Efficiency assessment for torrent protection works An approach based on safety and reliability analysis, 12th Congress Interpraevent, $11 \mathrm{p}$.

22. PPR of the municipality of Bramans, Savoie. (2014): detailed report, hazard map, land-use map, regulation.

23. PPR of the municipality of La-Salle-les-Alpes, Hautes-Alpes. (2009): detailed report, hazard map, land-use map, regulation.

24. Piton G., Carladous S., Recking A., Tacnet J-M., Liebault F., Kuss D., Quefféléan Y. and Marco O. (Sub. to). Why do we build check dams? An historical perspective from the French experience. Earth Surface Processes and Landforms, 23 p.

25. Piton G. and Recking A. (2015). Design of sediment traps with open check dams. I: Hydraulic and deposition processes, Journal of Hydraulic Engineering (ASCE), 16 p.

26. Hübl J. and Suda J. (2008). Debris flow mitigation measures in Austria, in: Sevkavgiprovodkhoz Institute (Ed.), Debris Flows Disasters, Risk, Forecast, Protection. Pyatigorsk., pp. 27-30.

27. Tacnet J.-M., Richard D., Dezert J. and BattonHubert M. (2010). Decision support and information fusion for expert assessment of natural risks: analysis of the efficiency of civil engineering protection works, Proceedings of the $6^{\text {th }}$ JFMS Conf., pp. 24-26. [In French].

28. Carladous S., Tacnet J.-M., Eckert N., Curt C. and Batton-Hubert M. (2014). Vers une analyse intégrée de l'efficacité des ouvrages de protection contre les risques naturels en montagne: évaluation économique en complément des volets structurels et fonctionnels. Proceedings of the $8^{\text {th }}$ JFMS Conf., pp 61-72. [In French].

29. Vidaud-Barral L., Deschâtres M., Bonnefoy M. and Richard D. (2010). Improving the interoperability and user-friendliness of the French snow avalanche information systems, International Snow Science Workshop (ISSW), Squaw Valley, Colorado, USA, pp. 17-22. 